\title{
An analysis of changes in flood quantiles at the gauge Neu Darchau (Elbe River) from 1875 to 2013
}

\author{
Christoph Mudersbach ${ }^{1,2}$, Jens Bender ${ }^{2,3}$, and Fabian Netzel ${ }^{1}$ \\ ${ }^{1}$ Bochum University of Applied Sciences, Institute for Water and Environment Lennershofstr. 140, \\ 44801 Bochum, Germany \\ ${ }^{2}$ wbu consulting Ingenieurgesellschaft mbH, Schelderberg 16a, 57072 Siegen, Germany \\ ${ }^{3}$ University of Siegen, Research Institute for Water and Environment, Paul-Bonatz-Str. 9-11, \\ 57076 Siegen, Germany \\ Correspondence to: Christoph Mudersbach (christoph.mudersbach@hs-bochum.de) \\ and Jens Bender (bender@wbu-consulting.de) \\ Published: 12 May 2016
}

\begin{abstract}
Within this investigation, we focus on a detailed analysis of the discharge data of the gauge Neu Darchau (Elbe River). The Elbe River inflows onto the North Sea. The gauge Neu Darchau is the most downstream discharge gauge of the Elbe River before it becomes an estuary. We follow the questions, whether the discharge characteristics of the Elbe River have changed over the last decades and how much common flood quantiles (i.e. 100-year flood) are affected by the latest extreme events in 2002, 2006, 2011, and 2013. Hence, we conduct (i) trend and seasonality analysis and (ii) an assessment of time-dependencies of flood quantiles by using quasi non-stationary extreme value statistics with both block maxima and peak-over-threshold approaches. The (iii) significance of the changes found in flood quantiles are assessed by using a stochastic approach based on autoregressive models and Monte Carlo simulations. The results of the trend analyses do show no clear evidences for any significant trends in daily mean discharges and increasing flood frequencies. With respect to the extreme events in 2002, 2006, 2011, and 2013 our results reveal, that those events do not lead to extraordinary changes in the 100-year floods. Nevertheless, in the majority an increase in the 100-year floods over the recent decades can be stated. Although these changes are not significant, for many time series of the 100-year flood quantiles there is a clear tendency towards the upper confidence band.
\end{abstract}

\section{Introduction}

During the last decades several severe floods occurred in different river basins in Germany (e.g. 1993 and 1995 Rhine; 1997 Odra; 1999, 2001, 2006 and 2013 Danube, 2002, 2006, 2011 and 2013 Elbe) (Petrow and Merz, 2009). In a public perception, there seems to be a trend to more frequent hydrological extreme events resulting in a rising flood hazard.

Thus, the questions arise whether the flood frequencies of the Elbe River have changed over the last decades and how much the design discharges (i.e. the 100-year flood) are affected?

Many recent studies focused on trend estimations in flood magnitude, frequency and seasonality of European or German rivers (e.g. Mudelsee et al., 2003, 2004; Petrow et al., 2009; Petrow and Merz, 2009; Beurton and Thieken, 2009; Stahl et al., 2010; Bormann et al., 2011). Mudelsee et al. (2003) investigated discharge data sets from the Elbe and Odra River for the past 80 to 150 years. For the Elbe River (gauge Dresden), they found a decreasing trend in winter floods, while summer floods do not show any significant trend.

Interestingly, although the extreme values are of major importance for river training, flood risk management and design purposes there is a lack of publications covering the aspect of changes in extreme flood quantiles (e.g. 100-year flood). In this paper we would like to make a contribution to close this gap. 
In order to gain the above mentioned objective we analyse the development of the 100-year flood quantile based on different flood indicators over time. Since we use the terms flood indicator, flood frequency indicator and flood quantile in this paper we first define them as follows:

A flood indicator is a time series of observed peak discharges of independent flood events. For gaining flood indicators several methods are commonly used, such as the block maxima approach or the peak-over-threshold approach. In this paper we use six different flood indicators. In addition, we calculate one flood frequency indicator, which is defined as the number of flood events per year exceeding a certain threshold. Separated from the flood indicator a flood quantile is defined as a statistically calculated flood event - by means of extreme value theory - with a certain exceedance probability (e.g. 100-year flood). The calculation of flood quantiles is based on the flood indicators.

In this paper we perform the following steps (applied to the gauge Neu Darchau):

- trend and seasonality analysis of daily mean discharges

- trend analysis of the flood frequency indicator

- assessment of time-dependent changes in flood quantiles (100-year flood) based on six different flood indicators by using extreme value statistics with both, block maxima (Generalized Extreme Value distribution, GEV) and peak-over-threshold (Generalized Pareto distribution, GPD) approach

- an estimation of confidence levels for the timedependent flood quantiles by means of Monte-Carlo simulations using autoregressive models.

More details of this investigation can be found in Mudersbach et al. (2015).

\section{Data}

\subsection{Daily mean discharge data}

Within this investigation, we do not perform spatial analyses of different discharge data sets over Europe or Germany, but focus on detailed analyses of the discharge data of the gauge Neu Darchau (Elbe River). The gauge Neu Darchau is the most downstream discharge gauge of the Elbe River before it becomes an estuary. The gauge is considered as a benchmark for the total discharge of the Elbe River (WSA Lauenburg, 2012). Thus, the discharge statistics of this gauge is of special importance for all designing purposes downstream of this location. Particular demands to design approaches are existent, e.g. due to nuclear power plants, the tidal weir at Geesthacht and the flood protection of Hamburg. The main threat of extreme floods downstream of the weir Geesthacht in the Elbe River evolves from storm surges from the North Sea. However, the river discharge is also one important parameter in

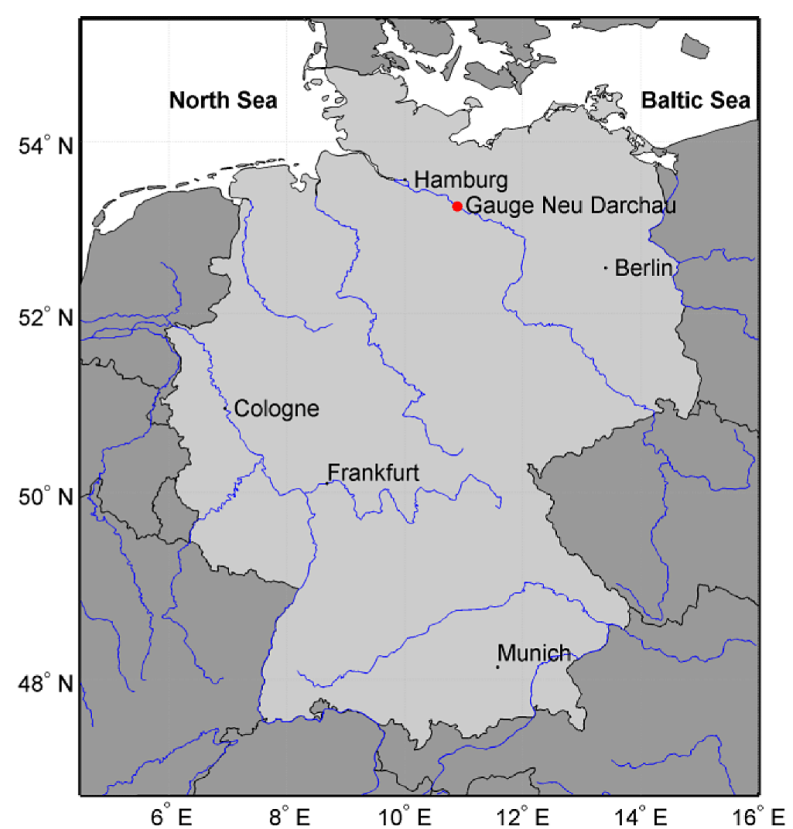

Figure 1. Location of gauge Neu Darchau at the Elbe River.

design approaches, especially if a storm surge coincides with a high river discharge.

The discharge data from the gauge Neu Darchau at Elbe location $536.4 \mathrm{~km}$ (Fig. 1) were obtained from the Water and Shipping Office Lauenburg (WSA Lauenburg), which is the official gauge operator. The records comprise daily mean discharge values from 1 November 1874 to 31 October 2013 (hydrological year in Germany: 1 November to 31 October), resulting in a time series covering 139 years without any gaps. The discharge measurements operate regularly since 1874 without any discontinuities. Since 1 November 1997 data with a resolution in time of $15 \mathrm{~min}$ are available. Prior to that, several measurements per day (not equally distributed) are the basis for the daily mean discharge data. Since the catchment size amounts to $131950 \mathrm{~km}^{2}$, these daily measurements are also suitable for deriving flood quantiles (Bender et al., 2015).

The most extreme flood was recorded on 25 March 1888 with $\mathrm{HHQ}=4400 \mathrm{~m}^{3} \mathrm{~s}^{-1}$. Since it was a severe winter flood, it is known that during this event an ice jam significantly influenced the flood stage measurement at gauge Neu Darchau (WSA Lauenburg, 2012). For this flood event the WSA Lauenburg provides a corrected peak discharge of $2310 \mathrm{~m}^{3} \mathrm{~s}^{-1}$ on 24 March 1888 instead of $4400 \mathrm{~m}^{3} \mathrm{~s}^{-1}$ on 25 March 1888 (N. Rölver, personal communication, 2012). We decided to use this corrected value instead of the original value, since the original - and obviously incorrect - value would significantly affect the extreme value statistics. Figure 2 illustrates the corrected daily mean discharge series at gauge Neu Darchau from 1875 to 2013. 


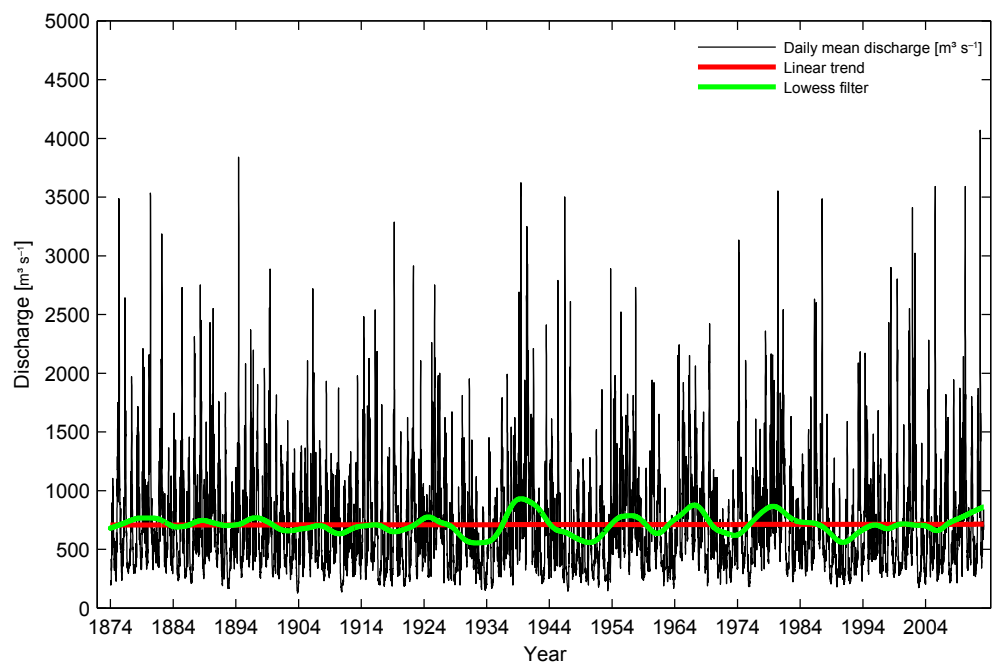

Figure 2. Daily mean discharge of gauge Neu Darchau from 1875 to 2013 with linear and non-linear trend (LOWESS, span $=10$ years).

The severe flood events on 23 August 2002 ( $Q=$ $\left.3410 \mathrm{~m}^{3} \mathrm{~s}^{-1}\right), 9$ April $2006\left(Q=3590 \mathrm{~m}^{3} \mathrm{~s}^{-1}\right), 23$ January $2011\left(Q=3593 \mathrm{~m}^{3} \mathrm{~s}^{-1}\right)$, and 11 June $2013(Q=$ $4070 \mathrm{~m}^{3} \mathrm{~s}^{-1}$ ) may lead to the assumption, that extreme events occurred more frequently within the last 15 years. While the floods in 2006 and 2011 occurred within the typical flood period (December-May), the severe floods in 2002 and 2013 occurred during summer. It is worthwhile to mention, that the 2013 event is a new record, i.e. this value is higher than all values observed before. Even if the latest extreme events in 2002, 2006, 2011 are very noticeable, the time series reveals that extreme floods with a comparable magnitude already occurred in former years.

\subsection{Flood indicators and flood frequency indicators}

Six flood indicators are analysed in this study using both, the block maxima and the peak-over-threshold (POT) approach (e.g. Leadbetter, 1991; Bayliss and Jones, 1993; Coles, 2001). The most common flood indicator in flood trend studies is the annual maximum discharge, i.e. the largest daily mean discharge that occurs in each hydrological year. This flood indicator is labelled as AMF. The annual maxima approach has extensively been used in the past (e.g. Acero et al., 2011). However, it can be a wasteful method if further data of extremes are available (Coles, 2001). Conversely, if no extreme flood occurs within a year, the maximum value will still be selected. To overcome these shortcomings, some alternative approaches came up in hydrological statistics.

In the $r$-largest approach (e.g. Smith, 1986; Coles, 2001), not only the annual maxima $(r=1)$ are considered in the sample, but e.g. the two $(r=2)$ or three $(r=3)$ largest annual values. The advantages and disadvantages of this method are obvious. Given a year with several extreme floods, using the $r$-largest method extends the data basis by including more of the available information concerning extreme discharge events. In contrast, if a year has no major floods, using the $r$-largest approach still considers the $r$ largest events of this year within the sample.

The POT approach (also known as partial duration series) provides a more flexible representation of floods compared to the AMF approach, since it accounts for stochastically and unequally distributed occurrences of floods. A POT sample is created using all independent values exceeding a predefined threshold $u$. The main advantage of the POT approach is therefore the consideration of all severe floods within a flood intensive year, while years with no extreme events are neglected. Thus, a POT time series captures more information concerning the entire flood characteristics of a river than using AMF. The key challenge of the POT approach, however, is the threshold selection, since statistical methods (e.g. extreme value distribution) may react very sensitive to different thresholds. Selecting suitable thresholds is therefore a complex task representing the main difficulty associated with the POT approach.

A common threshold selection criteria is to use a standard frequency factor $f$, so that the threshold $u$ can be estimated from the daily mean discharge series $Q$ by:

$u=\mu_{Q}+f \cdot \sigma_{Q}$

where $\mu_{Q}$ and $\sigma_{Q}$ are the mean and standard deviation of the daily mean discharge series $Q$, respectively. Rosbjerg and Madsen (1992) prefer to use a standard frequency factor of $f=3$, but take care for the condition $N \geq 2$.

We use the standard frequency factors $f=0.78, f=1.23$ and $f=2.18$, leading to a mean number of floods per year of $N=3, N=2$, and $N=1$, respectively. Although the factor $f=2.18(N=1)$ violates the condition $N \geq 2$, we also consider this factor for comparing with the AMF data set. Hence, we name the partial series as POT-0.78, POT-1.23, and POT- 
2.18. For flood frequency analyses we make use of the flood frequency indicator POT- $0.78 \mathrm{~F}$ which counts the number of floods per year exceeding the threshold $u=\mu_{Q}+0.78 \cdot \sigma_{Q}$.

\section{Methods}

For trend estimation of the daily mean discharge data and the flood frequency indicator we used linear regressions with an ordinary least square estimation technique. The significance of the trends was tested using the Mann-Kendall test (Mann, 1945; Kendall, 1975) on the $95 \%$ confidence level. In addition, we fitted a non-linear function to the daily mean discharge time series, using locally weighted scatterplot smoothing (LOWESS). The applied LOWESS function fits simple models to localized subsets of the data using linear least-squares fitting and a first-degree polynomial (Cleveland, 1981).

Nowadays, the Generalized Extreme Value distribution (GEV) and the Generalized Pareto distribution (GPD) have been established as the main distribution functions for extreme value statistics (e.g. Coles, 2001).

We use the maximum likelihood estimation (MLE) method to estimate the distribution parameters (Smith, 1986; Hosking and Wallis, 1997; Davison and Smith, 1990).

As introduced in Sect. 1 we try to clarify, how the flood quantiles have changed over the last decades. Timedependent changes in flood quantiles can be investigated using non-stationary statistical extreme value approaches (e.g. Mendez et al., 2007; Mudersbach and Jensen, 2010; Bender et al., 2014). However, in order to reflect the real situation in statistical or engineering practice, where design values are mainly determined by use of stationary extreme value approaches, here we use a quasi non-stationary extreme value approach in order to analyse the influence of new extreme events on the flood quantiles. The quasi non-stationary approach is based on the above mentioned stationary extreme value distributions (i.e. GEV and GPD) and a stepwise analysis of different time series lengths by what the uncertainties over time can be assessed. This approach is supported by Serinaldi and Kilsby (2015), who recommend a suitable uncertainty assessment accounting to temporal persistence when using stationary extreme value models. For our approach, firstly, flood quantiles using stationary extreme value statistics are computed for a time period from 1875 to 1950 . Afterwards, the time series is extended incrementally by one year until the entire time series from 1875 to 2013 is analysed. In this paper we only focus on the $Q_{0.99}$ flood quantile (i.e. 100-year flood).

As a result of the quasi non-stationary method we derive time series of the 100-year flood based on the different flood indicators. With only these information one can assess whether any time-dependent behaviour exists. However, the question which cannot be answered is, whether the observed changes are significant or not. To overcome this

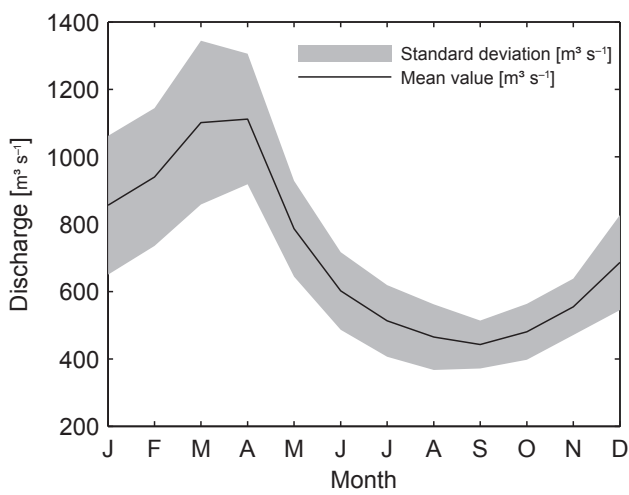

Figure 3. Seasonal cycle of monthly mean discharge data (black line) with corresponding standard deviation of gauge Neu Darchau from 1875 to 2013.

shortfall, one need appropriate confidence bands for the 100year flood time series. This confidence bands can be calculated by applying the following approach: Having a large set of independent synthetic daily mean discharge data of the gauge Neu Darchau, one may compare the calculated 100year floods from the original series with quantiles of the 100year flood values calculated from the large synthetic data set. Synthetic data sets can be simulated using autoregressive models, which have been used widely in hydrological time series analysis (e.g. Salas, 1980; Hosking, 1984; Maidment, 1992; Modarres, 2007; Lohani et al., 2012; Malamud and Turcotte, 2012). Thus, we simulate a large data set of synthetic daily mean discharges by using autoregressive (AR) models following Maidment (1993).

Using an AR3-model we can simulate a set of synthetic time series. Here, we simulate 200 synthetic daily discharge series with a length of 139 years. For all synthetic time series the same analyses as for the original discharge time series are repeated. For calculating the confidence bands we chose the $90 \%$ quantile of the resulting 100-year flood time series from the synthetic data sets. Thus, the calculation of the confidence bands is independent from the calculation of the 100year flood quantiles from the observed data. This procedure enables one to assess, whether the flood quantiles of the observed data show any significant changes in comparison to an (assumed) homogeneous hydrological system, which is represented by the synthetic time series.

\section{Results}

\subsection{Trends in daily mean discharge and seasonal cycle}

The overall mean of the daily mean discharge from 1875 to 2013 (hydrological years) amounts to $\mathrm{MQ}=710 \mathrm{~m}^{3} \mathrm{~s}^{-1}$ with a standard deviation of $s=446 \mathrm{~m}^{3} \mathrm{~s}^{-1}$ (Fig. 2). The linear trend is non-significant at the $95 \%$ confidence level. The LOWESS filter with a filter span of 10 years illustrate, that the series can be intersected into two periods. A first one 

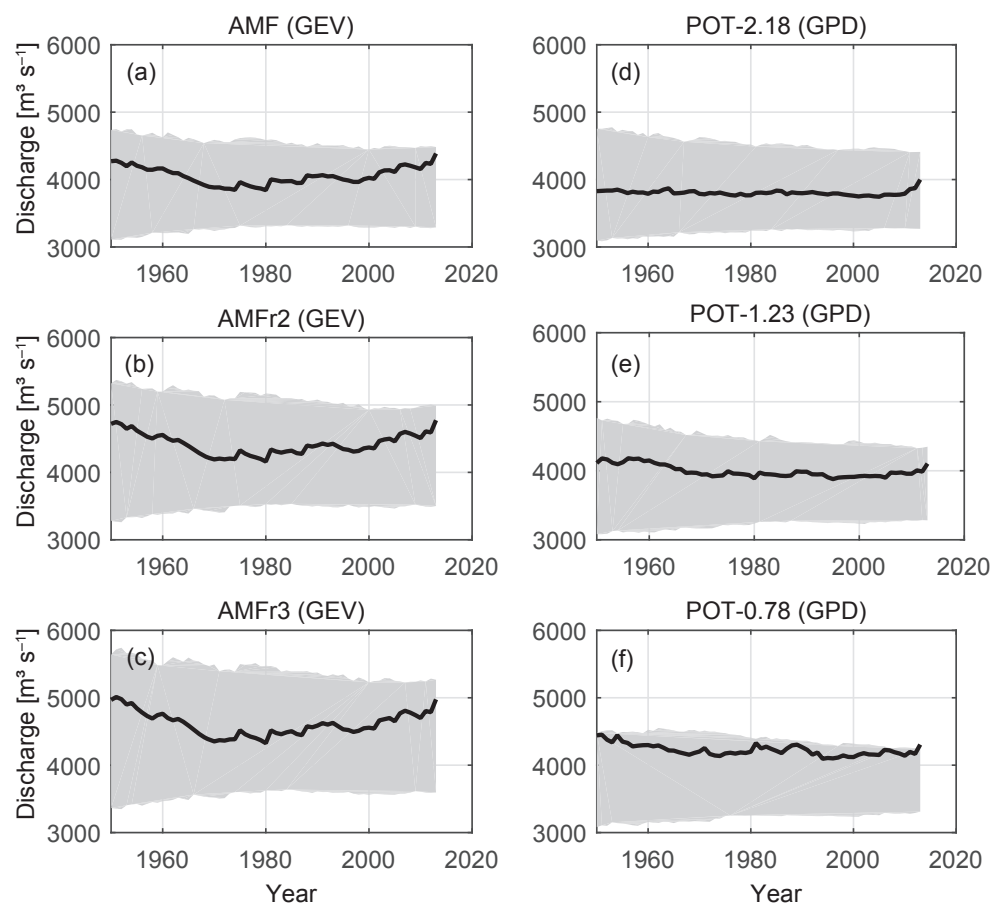

Figure 4. Time-dependent 100-year floods (thick black line) from 1950 to 2013 derived by extreme value statistics and the different flood indicators. The grey area refer to the $90 \%$ confidence levels.

from 1875 to about 1920, where a rather small variance exists, followed by a period up to the end with higher magnitudes. Interannual or decadal variations in discharges may be explained to a certain extend by the North Atlantic Oscillation (NAO) (Villarini et al., 2011; Ionita et al., 2011).

As the annual cycle contributes to the largest of all variations in the discharges, the annual cycle is analysed more in detail in Fig. 3, which shows the mean values (thick black line) of each month from 1875 to 2013. The grey line represents the associated standard deviation. Maximum discharge values occur in March and April, with mean values of $\mathrm{MQ}_{\text {March }}=1101 \mathrm{~m}^{3} \mathrm{~s}^{-1}$ and $M Q_{\text {April }}=1112 \mathrm{~m}^{3} \mathrm{~s}^{-1}$. The minimum value appears in September with $\mathrm{MQ}_{\text {September }}=443 \mathrm{~m}^{3} \mathrm{~s}^{-1}$. The standard deviation is also largest in March and April. The winter season is therefore the most important season for the genesis of floods. Trend estimates with standard errors are performed for each month and the significance is tested at a $95 \%$ confidence level using the Mann-Kendall test (not shown). The results indicate that there is no evidence for general changes with time. Except for the month May, no significant trends can be found at the $95 \%$ confidence level. Since the trend in May is also rather small, there seems to be no physical reason. It is worthwhile to mention, that there is a tendency for a positive trend in the summer season and a negative trend in the winter season.

The overall results of analysing the daily mean (not the extreme) discharge data indicate, that there are considerable an- nual to decadal variations existent, but no clear evidence for any long term trend in the discharge characteristics is given. As a conclusion, there is no need to reject the Neu Darchau data set for any ongoing statistical analyses, although many river regulations works may affect the time series.

\subsection{Changes in flood quantiles}

As introduced in Sect. 1 we try to clarify how flood quantiles have changed over the last decades at gauge Neu Darchau and whether these changes are significant or not. The basis for calculating the flood quantiles are the six flood indicators described in Sect. 2.2. A typical problem in stationary extreme value statistics is to find a trade-off between the extrapolation bias and the non-stationarity bias. The shorter a time series is, the more valid is the assumption of stationarity, but the uncertainty with extrapolating to high quantiles will rise significantly. Vice versa, the longer a time series is, the smaller the uncertainty with extrapolating to high quantiles, but the less valid is the assumption for stationarity. This problem was solved by two conditions: (1) the first time period analysed (1875 to 1950) has a length of 76 years, which is a reliable basis for determining the 100-year flood. (2) Each period is linearly detrended and is therefore considered as a stationary sample.

Figure 4 illustrates the results of the quasi non-stationary extreme value analysis for the six flood indicators POT- 0.78 , POT-1.23, POT-2.18, AMF, AMFr2, and AMFr3. The black lines represent the time-dependent development of the 100- 
year floods for each time span. This means, the first value plotted at the year 1950 is the 100-year flood resulting from 1875 to 1950 . The next value, plotted at 1951 , results from the time series 1875 to 1951 and so on.

The grey area refers to the $90 \%$ confidence bands calculated by means of autoregressive models and Monte-Carlo simulations.

Results from the AMF time series (Fig. 4a) shows a decreasing trend from 1950 to around 1980, followed by an increase until 2013. It can also be stated, that for the recent years a rather sharp increase can be observed. As the confidence bands depend on the underlying time series length, the confidence bands get smaller as the time series record increases. From 1980 to 2013 the 100-year flood time series steadily move towards the upper confidence band. In 2013, the 100-year flood series is still within the confidence bands but remains very close to the upper confidence band. The general characteristics of the AMFr2 (Fig. 4b) and AMFr3 (Fig. 4c) time series is comparable to the AMF time series. A remarkable difference can be seen in the absolute values of the 100-year floods. For example, for the year 2013 the 100year floods vary from $4384 \mathrm{~m}^{3}$ (AMF) to $4979 \mathrm{~m}^{3}$ (AMFr3), which is mainly a result of the different shape parameters of the GEV.

Results from analysing the POT-2.18 time series with the GPD (Fig. 4d) show a rather stationary behaviour from 1950 to 2009. From 2009 until 2013 there is a sharp increase of the 100 -year floods from approximately 3780 to $4005 \mathrm{~m}^{3}$. The confidence bands also get smaller with increasing time series length. In the POT-2.18 case the 100-year flood values move more or less in the mean range of the confidence bands. The results for the POT-1.23 time series (Fig. 4e) show not that stationary behaviour than for the POT-2.18 series. From 1950 to approximately 2000 there is a slight decrease of the 100year floods and a moderate increase until 2013. Results from analysing the POT-0.78 time series (Fig. 4f) with the GPD reveal a decreasing development of the 100-year floods from 1950 to about 2000 and a slight increase until 2013. However, for the whole time series there is a convergence to the upper confidence band, which is exceeded in 2013.

\section{Discussion and conclusions}

The main objective of this paper is to answer the questions, whether the flood frequencies of the Elbe River have changed over the last decades and how much the design discharges (i.e. the 100-year flood) are affected. Therefore, we use a quasi non-stationary extreme value approach flanked by Monte Carlo simulations in order to assess the significance of the changes found.

The results of the trend analyses reveal no clear evidences for increasing flood frequencies. These results point out, that the time series of the gauge Neu Darchau can be assumed as stationary. Of course, many river trainings works were con- ducted in the Elbe River over the last decades, which may lead to an inhomogeneous data set. Due to the fact, that the major part of these river training works took place in the upper part of the Elbe River, the effect on the downstream located gauge Neu Darchau is rather small. This basically confirms the findings from (Mudelsee et al., 2004) who analysed extreme floods in central Europe. A large number of dams in the upper part of the Elbe River catchment started their operation between 1900 and 1960. Since reservoirs damp the flood peak level due to retention effects, a dependency between the found reduction in flood quantiles and seasonal amplitude until 1980 and the reservoirs is very likely. Furthermore, Busch et al. (2012) found that the peak discharge of flood events can be reduced due to dam regulation up to 359 to $757 \mathrm{~m}^{3} \mathrm{~s}^{-1}$ at gauge Dresden and 183 to $616 \mathrm{~m}^{3} \mathrm{~s}^{-1}$ at the gauge Wittenberge (approximately $80 \mathrm{~km}$ upstream of gauge Neu Darchau). As we did not separate anthropogenic (e.g. river engineering/training) and climate change effects on the discharge data in our analyses, no quantitative statements regarding the interactions of these effects can be made. In addition, our results found for the gauge Neu Darchau are not directly transferrable to more upstream located gauges.

With respect to the extreme events in 2002, 2006, 2011, and 2013 the results from the quasi non-stationary extreme value approach reveal, that those events do not lead to extraordinary changes in the 100-year floods. Nevertheless, in the majority of the flood indicators an increase in the 100year floods over the last decades can be stated. Comparing the absolute values one can see that the more data a flood indicator contains (e.g. POT-0.78 and AMFr3) the higher the 100-year floods are.

From a more general point of view it is important to mention, that the stability of a flood with a given return period strongly depends on the analysed record length. The shorter the analysed time series, the larger the variability and the uncertainty of return discharge estimates. Merz et al. (2011) discussed this topic with respect to the return period of the 2002 flood at the Elbe River gauge Dresden. This phenomenon is also present in this study. To avoid large uncertainties in our analyses due to short time series we use as shortest time series a length of 76 years (1875 to 1950).

\section{References}

Acero, F. J., Garcia, J. A., and Cruz Gallego, M.: Peaks-over threshold study of trends in extreme rainfall over the Iberian, Peninsula, J. Climate, 24, 1089-1105, 2011.

Bayliss, A. C. and Jones, R. C.: Peaks-over-threshold flood database: Summary statistics and seasonality, Report No. 121, Institute of Hydrology, Wallingford, 1993.

Bender, J., Wahl, T., and Jensen, J.: Multivariate design in the presence of non-stationarity, J. Hydrol., 514, 123-130, 2014.

Bender, J., Mudersbach, C., and Jensen, J.: Verwendung diskreter Abflusszeitreihen für die Ermittlung von Bemes- 
sungshochwasserabflüssen, Tagungsband 38, Dresdner Wasserbaukolloquium, Dresdner Wasserbauliche Mitteilungen, 2015.

Beurton, S. and Thieken, A. H.: Seasonality of floods in Germany, Hydrolog. Sci. J., 54, 62-76, 2009.

Bormann, H., Pinter, N., and Elfert, S.: Hydrological signatures of flood trends on German rivers: Flood frequencies, flood heights and specific stages, J. Hydrol., 404, 50-66, 2011.

Busch, N., Balvin, P., Hatz, M., and Krejci, J.: Bewertung von Einflüssen tschechischer und thüringer Talsperren auf Hochwasser an Moldau und Elbe in Tschechien und Deutschland mittels Einsatz mathematischer Modelle, Technischer Bericht BfG-1725, Bundesanstalt für Gewässerkunde, Koblenz, 2012 (in German).

Cleveland, W. S.: Lowess - a Program for Smoothing Scatterplots by Robust Locally Weighted Regression, Am. Stat., 35, 54-54, 1981.

Coles, S.: An Introduction to Statistical Modeling of Extreme Values, Springer-Verlag, New-York, 2001.

Davison, A. C. and Smith, R. L.: Models for exceedances over high thresholds (with discussion), J. Roy. Stat. Soc. B, 52, 393-442, 1990.

Hosking, J. R. M.: Modeling persistence in hydrological time series using fractional differencing, Water Resour. Res., 20, 18981908, 1984

Hosking, J. R. M. and Wallis, J. R.: Regional frequency analysis. Cambridge University-Press. Cambridge, 1997.

Ionita, M., Rimbu, N., and Lohmann, G.: Decadal variability of the Elbe River streamflow, Int. J. Climatol., 31, 22-30, 2011.

Kendall, M. G.: Rank Correlation Methods, Griffin, London, 1975.

Leadbetter, M. R.: On a basis for "Peaks over Threshold modeling", Stat. Probabil. Lett., 12, 357-362, 1991.

Lohani, A. K., Kumar, R., and Singh, R. D.: Hydrological time series modeling: A comparison between adaptive neuro-fuzzy, neural network and autoregressive techniques, J. Hydrol., 442-443, 23-35, 2012.

Malamud, B. D. and Turcotte, D. L.: Time Series: Analysis and Modelling, in: Environmental modelling. Finding simplicity in complexity, edited by: John Wainwright, J. and Mulligan, M., 2nd Edn., Chichester, West Sussex, Hoboken, NJ, Wiley, 2012.

Mann, H. B.: Nonparametric tests against trend, Econometrica, 13, 245-259, 1945.

Mendez, F., Menendez, M., Luceno, A., and Losada, I. J.: Analyzing monthly extreme sea levels with a time-dependent GEV Model, J. Atmos. Ocean. Tech., 24, 894-911, 2007.

Merz, B., Bittner, R., Grünewald, U., and Piroth, K.: Management von Hochwasserrisiken. Mit Beiträgen aus den RIMAXForschungsprojekten, Schweizerbart, Stuttgart, 2011 (in German).
Modarres, R.: Streamflow drought time series forecasting, Stoch. Env. Res. Ris. A., 21, 223-233, 2007.

Mudelsee, M., Börngen, M., Tetzlaff, G., and Grünewald, U.: No upward trends in the occurrence of extreme floods in central Europe, Nature, 425, 166-169, 2003.

Mudelsee, M., Börngen, M., Tetzlaff, G., and Grünewald, U.: Extreme floods in central Europe over the past 500 years: Role of cyclone pathway "Zugstrasse Vb", J. Geophys. Res., 109, D23101, doi:10.1029/2004JD005034, 2004.

Mudersbach, C. and Jensen, J.: Non-stationary extreme value analysis of annual maximum water levels for designing coastal structures at the German North Sea coastline, Journal of Flood Risk Management, 3, 52-62, 2010.

Mudersbach, C., Bender, J., and Netzel, F.: An analysis of changes in flood quantiles at the gauge Neu Darchau (Elbe River) from 1875 to 2013, Stoch. Env. Res. Ris. A., doi:10.1007/s00477-0151173-7, online first, 2015.

Petrow, T. and Merz, B.: Trends in flood magnitude, frequency and seasonality in Germany in the period 1951-2002, J. Hydrol., 371, 129-141, 2009.

Petrow, T., Zimmer, J., and Merz, B.: Changes in the flood hazard in Germany through changing frequency and persistence of circulation patterns, Nat. Hazards Earth Syst. Sci., 9, 1409-1423, doi:10.5194/nhess-9-1409-2009, 2009.

Rosbjerg, D. and Madsen, H.: On the choice of threshold level in partial durations series. XVII Nordic Hydrological Conference, Alta, Norway, NHP Rep no. 30, 604-615, 1992.

Salas, J. D.: Applied modeling of hydrologic time series, Water Resources Publication, Littleton, 1980.

Serinaldi, F. and Kilsby, C. G.: Stationarity is undead: Uncertainty dominates the distribution of extremes, Adv. Water Resour., 77, 17-36, 2015.

Smith, R. L.: Extreme Value Theory Based On The Largest Annual Events, J. Hydrol., 86, 27-43, 1986.

Stahl, K., Hisdal, H., Hannaford, J., Tallaksen, L. M., van Lanen, H. A. J., Sauquet, E., Demuth, S., Fendekova, M., and Jódar, J.: Streamflow trends in Europe: evidence from a dataset of nearnatural catchments, Hydrol. Earth Syst. Sci., 14, 2367-2382, doi:10.5194/hess-14-2367-2010, 2010.

Villarini, G., Smith, J. A., Serinaldi, F., and Ntelekos, A. A.: Analyses of seasonal and annual maximum daily discharge records for central Europe, J. Hydrol., 399, 299-312, 2011.

WSA Lauenburg: Official website of the gauge operator, available at: http://www.wsa-lauenburg.wsv.de (last access: 13 November 2013), 2012. 